\title{
RETRACTED ARTICLE: Urinary nerve growth factor: a biomarker for overactive bladder in children? A meta-analysis and trail sequential analysis
}

\author{
Changkai Deng ${ }^{1} \cdot$ Qiang Peng $^{1} \cdot$ Xianliang $\mathrm{Hu}^{1} \cdot \mathrm{Li} \mathrm{Gao}^{1} \cdot$ Juan $\mathrm{Xu}^{1} \cdot$ Jing Su$^{1} \cdot \mathrm{Xue} \mathrm{Xia}^{1} \cdot \mathrm{Feng} \mathrm{Liu}^{2} \cdot \mathrm{Maoxian}^{\mathrm{Li}}{ }^{1}$
}

Accepted: 25 January 2019 / Published online: 19 February 2019

(c) Springer-Verlag GmbH Germany, part of Springer Nature 2019

The editor has retracted this article because the article shows significant overlap with another publication [1] by the same corresponding author. All authors agree to the retraction. The online version of this article contains the full text of the retracted article as electronic supplementary material. [1] Deng, C., Zhang, W., Peng, Q. et al. Pediatr Surg Int (2019). https://doi.org/10.1007/s00383-019-04448-7

Electronic supplementary material The online version of this article (https://doi.org/10.1007/s00383-019-04447-8) contains supplementary material, which is available to authorized users.

\section{Changkai Deng}

295969893@qq.com

1 Department of Pediatric Surgery, Chengdu Women's and Children's Central Hospital of Chongqing Medical University, No. 1617, Riyue Avenue, Qinyang District, Chengdu, China

2 Department of Urology Surgery, Children's Hospital of Chongqing Medical University, Chongqing, China 